\title{
HBsAg loss in chronic hepatitis B: pointers to the benefits of curative therapy
}

\author{
Geoffrey Dusheiko $^{1,2} \cdot$ Bo Wang ${ }^{1} \cdot$ Ivana Carey $^{1}$
}

Received: 5 April 2016/Accepted: 8 May 2016/Published online: 31 May 2016

(C) Asian Pacific Association for the Study of the Liver 2016

Hepatitis B surface antigen ( $\mathrm{HBsAg}$ ) clearance is a relatively rare outcome during the complex natural history of chronic hepatitis B [1]. The estimated annual incidence of clearance of HBsAg is 1-2\% in Asian and in Western populations [2]. Annual rates of HBsAg loss in HBeAgnegative patients may be higher in those with lower levels of hepatitis B replication, minimal hepatitis and normal serum aminotransferases [3]. Hepatitis B genotype and mode of acquisition may influence the rate of HBsAg loss. Spontaneous seroclearance of HBsAg is thought to be beneficial, and to confer an improved outlook; thus HBsAg concentrations and loss may be a useful biomarker of prognosis in patients with chronic hepatitis B [4]. HBsAg loss may also occur, although relatively rarely, after interferon-alpha treatment or nucleoside analogue anti-viral therapy [5-7]. Likewise, the prognosis is improved, and thus HBsAg loss, rather than merely HBV DNA suppression, has become an important goal of potential curative therapies for hepatitis B.

However, patients who have become HBsAg negative can nonetheless develop hepatocellular carcinoma (HCC), although the risk is diminished compared to those with persistent HBsAg positivity [8]. The risk of HCC is greater in those with established cirrhosis or older age. It should be remembered that the lack of detectable HBsAg in serum depends upon the sensitivity of the assay [9]. HBsAg loss is usually durable. It is recognised that intrahepatic HBV genomes may persist in HBsAg-negative individuals: both covalently closed circular (ccc) DNA and integrated

Geoffrey Dusheiko

g.dusheiko@ucl.ac.uk

1 Kings College Hospital, London, UK

2 University College London Medical School, London, UK hepatitis B viral genomes may persist in the liver after HBsAg clearance from serum [10]. Consequently, reactivation may occur either spontaneously, and importantly, after chemotherapy in patients with hematological and solid malignancies, or after immunosuppression in $\mathrm{HBsAg}$ negative, anti-HBc positive persons [11].

In this study from New Zealand Lim and colleagues [12] report the long-term rates of HBsAg loss and outcomes, particularly HCC, in a cohort from the eastern Bay of Plenty in North Island in New Zealand. They also assessed the predictive value of baseline HBsAg levels compared to HBV DNA in predicting long-term HBsAg loss. The study examined a community cohort in which 572 patients with chronic hepatitis B were identified and followed for a prolonged period of 28 years. The database was established in 1984 , after $93 \%$ of 8,514 persons over the age of 6 months were tested for current and past hepatitis B infection. Seventy-nine percent of the cohort were Polynesian, $21 \%$ Caucasian and $63 \%$ were male. In this cohort, $6.1 \%$ were confirmed as having chronic hepatitis B, and at the outset of the study, $48 \%$ were HBeAg-positive. All were entered into a long-term follow-up study, with six monthly blood tests. The median age of the participants in the study at enrolment was 17 years. The predominant genotype in this population is $\mathrm{C}$ and $\mathrm{D}$. Interestingly in $79 \%$ of the cohort, serum alanine aminotransferases were normal but only $11 \%$ had HBV DNA concentration of less than $2000 \mathrm{IU} / \mathrm{mL}$ at baseline. Spontaneous HBsAg loss had occurred in 145/572 individuals $(33 \%)$ after 12,702 person-years of follow-up. The majority had developed anti-HBs. No HCC has been observed following HBsAg loss in the cohort after a median follow-up of 72 months. The main predictors of HBsAg loss were older age and a lower baseline $\mathrm{HBsAg}$; in particular, the HBsAg level hazard ratio for HBsAg loss over 28 years was 2.7 for HBsAg concentrations of 1000-10,000 IU/mL, 6.7 
for concentrations of $100-1000 \mathrm{IU} / \mathrm{mL}$ but 9.4 for $\mathrm{HBsAg}$ concentrations of $<100 \mathrm{IU} / \mathrm{mL}$ (compared to $\mathrm{HBsAg}$ concentrations $>10,000 \mathrm{IU} / \mathrm{mL}$ ). The annual rate of loss of $\mathrm{HBsAg}$ in patients with HBsAg levels below $100 \mathrm{IU} / \mathrm{mL}$ was $5.7 \%$ compared to $0.5 \%$ in persons with HBsAg concentration of $>10,000 \mathrm{IU} / \mathrm{mL}$. Seventeen percent of those with HBsAg loss were originally HBeAg-positive in 1984.

Quantitation of HBsAg thus offers an opportunity to predict outcome. The analysis self-fulfils a prophecy that lower HBsAg levels are associated with a greater likelihood of HBsAg becoming undetectable in serum during followup [13]. It is remarkable that only 25 patients (4\%) of the entire HBsAg positive cohort had received anti-viral therapy by 2012 . The reason given by the authors was that antiviral therapies were not available. (None of those treated with anti-viral therapy lost HBsAg). The very low rate of treatment in this cohort is somewhat surprising: does this point to the possibility that a high proportion of individuals in this community study had what was considered inactive disease, not meriting anti-viral therapy? Thus this interesting and unique study from New Zealand largely reflects events in an untreated population, but the analysis may also have selected for a population that did not require treatment because of relatively inactive disease. The data indicate that clinical outcomes were particularly favourable in those in whom HBsAg clearance had occurred at a relatively young age. Liver stiffness measurements obtained by transient elastography were significantly lower if HBsAg loss occurred in those younger than 40 compared to those older than 40 years.

The REVEAL studies demonstrated a linear reduction in HCC risk with reductions in HBV DNA levels. Newer predictive models incorporating baseline $\mathrm{HBsAg}$ as well as HBV DNA to examine the probability of later disease or the risk of HCC are being developed [14]. This unique data from New Zealand provides important outcomes from a prolonged follow-up study, in a sizeable cohort of HBsAg positive persons, but leaves open several important questions of the mechanisms of HBsAg clearance. The data do not clarify the serial, longitudinal declines in HBsAg concentrations during the phases of the natural history of the disease, and the absence of serial measurements in the analysis does not clarify any decline in HBsAg concentrations during a stepwise process of spontaneous decreases in HBV-DNA concentrations, or seroconversion from $\mathrm{HBeAg}$-positive disease to anti-HBe disease, and eventual HBsAg loss in the $\mathrm{HBeAg}$ positive cohort. For example, did the kinetics of HBsAg loss differ, perhaps as a result cell turnover, during the immune active phase in the $\mathrm{HBeAg}$ positive patients with high and then lowered levels of HBV replication compared to those with anti-HBe positive disease [15]. Can HBsAg loss be predicted after HBeAg loss [16]?

As we attempt to develop curative immune-modulatory and molecular therapies for hepatitis B, it will be important to better understand the in situ molecular intrahepatic virological (and immunological) events that presage and accompany a decline in HBsAg concentrations [17, 18]. cccDNA is the transcriptional template for transcription of viral RNA, and the relative resistance of cccDNA to treatment with chain terminators precludes cure in most patients treated with nucleoside analogue therapy. Hepatocyte turnover is a factor in cccDNA decay: Does cccDNA persist in the nucleus of infected cells without amplification to multiple copies in patients losing $\mathrm{HBeAg}$ and then HBsAg? What continued transcription occurs from integrated viral genomes? In patients with spontaneous, albeit slow declines in HBsAg concentrations, is the absolute quantity and reservoir of cccDNA stable, but transcription from cccDNA silenced by epigenetic modification [19]? Does all cccDNA chromatin require clearance for a cure of hepatitis B, or do most individuals continue to replicate low threshold levels that are insufficient to express detectable HBsAg and thus result in a slowing of the disease? To what extent do the molecular events reflect control by immunological targeting, or conversely do molecular changes lead to a reduction of the high HBsAg antigen load to allow restoration of $\mathrm{T}$ cell activation and recovery from a dysfunctional immune response? What are the influences of HBV genotype on these events? Critical surrogates of cccDNA function and concentration are required.

Several recent studies have indicated that HBsAg seroconversion occurring in those who are older or who have advanced fibrosis and cirrhosis are still at risk of HCC, although that risk is lowered [20]. Patients with cirrhosis on continuous antiviral therapy require ongoing surveillance; such surveillance is deemed generally "cost-effective" if the expected annual incidence exceeds an accepted threshold, so that surveillance at 6 months intervals is usually required. The data in this population point to a guideline whereby the burden of continuous imaging and surveillance for HCC may be refined. The data from this analysis suggest that patients who have cleared $\mathrm{HBsAg}$ could have transient elastography or other measure of hepatic fibrosis; patients with advanced fibrosis, or cirrhosis will require ongoing surveillance for HCC whereas HBsAg loss in patients with lesser degrees of fibrosis may not require ongoing surveillance. Perhaps HBsAg loss at a young age may allow an extension of surveillance intervals in younger patients with cirrhosis prior to therapy [21].

Importantly the study provides indirect evidence that new curative therapies that result in loss, or diminution, of HBsAg will improve clinical outcomes [14]. The data indicate that HBsAg clearance can occur after a prolonged period of disease, but to improve clinical outcomes we will need to seek to cure active hepatitis at an age well before the onset of severe fibrosis, to limit the consequences of 
necro-inflammatory change in the liver and intrahepatic events accompanying HBV DNA into the host chromosome. Such a strategy, and the means to effect loss of HBsAg at a young age, will reduce the residual likelihood of cirrhosis and of HCC and result in true cures of chronic hepatitis $\mathrm{B}$.

\section{References}

1. Liaw YF, Chu CM. Hepatitis B virus infection. Lancet 2009;373:582-592

2. Chu CM, Liaw YF. Hepatitis B surface antigen seroclearance during chronic HBV infection. Antivir Ther 2010;15:133-143

3. Liu J, Yang HI, Lee MH, Lu SN, Jen CL, Wang LY, You SL, et al. Incidence and determinants of spontaneous hepatitis B surface antigen seroclearance: a community-based follow-up study. Gastroenterology 2010;139:474-482

4. Yuen MF, Wong DK, Sablon E, Tse E, Ng IO, Yuan HJ, Siu CW, et al. HBsAg seroclearance in chronic hepatitis B in the Chinese: virological, histological, and clinical aspects. Hepatology 2004;39:1694-1701

5. Buti M, Tsai N, Petersen J, Flisiak R, Gurel S, Krastev Z, Schall RA, et al. Seven-year efficacy and safety of treatment with tenofovir disoproxil fumarate for chronic hepatitis B virus infection. Dig Dis Sci 2015;60:1457-1464

6. Kim GA, Lim YS, An J, Lee D, Shim JH, Kim KM, Lee HC, et al. HBsAg seroclearance after nucleoside analogue therapy in patients with chronic hepatitis B: clinical outcomes and durability. Gut 2014;63:1325-1332

7. Arase Y, Ikeda K, Suzuki F, Suzuki Y, Saitoh S, Kobayashi M, Akuta N, et al. Long-term outcome after hepatitis B surface antigen seroclearance in patients with chronic hepatitis B. Am J Med 2006;119:71.e79-16

8. Idilman R, Cinar K, Seven G, Bozkus Y, Elhan A, Bozdayi M, Yurdaydin C, et al. Hepatitis B surface antigen seroconversion is associated with favourable long-term clinical outcomes during lamivudine treatment in $\mathrm{HBeAg}$-negative chronic hepatitis B patients. J Viral Hepat 2012;19:220-226

9. Seto WK, Tanaka Y, Wong DK, Shinkai N, Cheung KS, Liu KS, Fung J, et al. Longitudinal profiles of highly sensitive hepatitis B surface antigen levels: re-evaluation of $\mathrm{HBsAg}$ seroclearance. Liver Int 2016;36(5):642-650

10. Saitta C, Tripodi G, Barbera A, Bertuccio A, Smedile A, Ciancio A, Raffa G, et al. Hepatitis B virus (HBV) DNA integration in patients with occult HBV infection and hepatocellular carcinoma. Liver Int 2015;35:2311-2317

11. Seto WK, Chan TS, Hwang YY, Wong DK, Fung J, Liu KS, Gill $\mathrm{H}$, et al. Hepatitis B reactivation in patients with previous hepatitis $\mathrm{B}$ virus exposure undergoing rituximab-containing chemotherapy for lymphoma: a prospective study. J Clin Oncol 2014;32:3736-3743

12. Lim TH, Gane E, Moyes C, Borman B, Cunningham C. HBsAg loss in a New Zealand community study with 28 -year follow-up: rates, predictors and long term outcomes. Hepatol Int. 2016. doi:10.1007/s12072-016-9709-6.

13. Tseng TC, Liu CJ, Su TH, Wang CC, Chen CL, Chen PJ, Chen DS, et al. Serum hepatitis B surface antigen levels predict surface antigen loss in hepatitis B e antigen seroconverters. Gastroenterology 2011;141:517-525, 525.e511-e512

14. Yang HI, Tseng TC, Liu J, Lee MH, Liu CJ, Su TH, BatrlaUtermann R, et al. Incorporating serum level of hepatitis B surface antigen or omitting level of hepatitis B virus DNA does not affect calculation of risk for hepatocellular carcinoma in patients without cirrhosis. Clin Gastroenterol Hepatol 2016;14(461-468):e462

15. Fung J, Seto WK, Wong DK, Lai CL, Yuen MF. Hepatitis B surface antigen levels after hepatitis B e-antigen seroclearance: a longitudinal follow-up study. Liver Int 2015;35:854-859

16. Liu J, Tseng TC, Yang HI, Lee MH, Batrla-Utermann R, Jen CL, $\mathrm{Lu} \mathrm{SN}$, et al. Predicting hepatitis B virus (HBV) surface antigen seroclearance in $\mathrm{HBV}$ e antigen-negative patients with chronic hepatitis B: external validation of a scoring system. J Infect Dis 2015;211:1566-1573

17. Revill PA, Locarnini SA. New perspectives on the hepatitis B virus life cycle in the human liver. J Clin Invest 2016; 126:833-836

18. Zhang X, Lu W, Zheng Y, Wang W, Bai L, Chen L, Feng Y, et al. In situ analysis of intrahepatic virological events in chronic hepatitis B virus infection. J Clin Invest 2016;126:1079-1092

19. Zhang Y, Mao R, Yan R, Cai D, Zhang Y, Zhu H, Kang Y, et al. Transcription of hepatitis B virus covalently closed circular DNA is regulated by cpg methylation during chronic infection. PLoS One 2014;9:e110442

20. Simonetti J, Bulkow L, McMahon BJ, Homan C, Snowball M, Negus S, Williams J, et al. Clearance of hepatitis B surface antigen and risk of hepatocellular carcinoma in a cohort chronically infected with hepatitis B virus. Hepatology 2010;51:1531-1537

21. Yuen MF, Wong DK, Fung J, Ip P, But D, Hung I, Lau K, et al. HBsAg Seroclearance in chronic hepatitis B in Asian patients: replicative level and risk of hepatocellular carcinoma. Gastroenterology 2008;135:1192-1199 